\title{
Effect of dietary-induced increases in circulating insulin concentrations during the early postpartum period on reproductive function in dairy cows
}

\author{
J. G. Gong1, W. J. Lee1, P. C. Garnsworthy² and R. Webb² \\ ${ }^{1}$ Roslin Institute (Edinburgh), Roslin, Midlothian EH25 9PS, UK; and ${ }^{2}$ School of Biosciences, \\ University of Nottingham, Sutton Bonington Campus, \\ Loughborough LE12 5RD, UK
}

\begin{abstract}
Although it has become increasingly clear that fertility in modern dairy cattle is declining in association with increased milk yields, the underlying mechanism is poorly understood. The first ovulation post partum is delayed in dairy cows undergoing selection for genetic merit for milk yield in association with lower circulating insulin concentrations. The aim of this study was to investigate whether feeding a diet to increase circulating insulin concentrations can overcome this delay in the first ovulation post partum. The experiment was a $2 \times 2$ factorial design ( $n=10$ per group) involving diet and genetic merit for milk yield. The dietary treatment started on the day of calving and lasted for 50 days. Plasma samples were collected each day and ovarian ultrasonography was performed three times a week during the experimental feeding period. Milk yield was recorded each day, and body weight and body condition score were determined each week. Milk samples were collected three times a week from day 50 to day 105 post partum, and reproductive performance data were recorded for all the cows as part of the routine farm practice. The dietary
\end{abstract}

treatment induced significant differences in plasma insulin concentrations in both high and low genetic merit cows. Although high genetic merit cows produced more milk, lost more body weight and had lower body condition scores during the experiment, no significant effect of diet was observed on these measurements. The high insulin inducing diet increased the proportion of cows ovulating within 50 days of calving and reduced the intervals from calving to first ovulation, and tended to reduce the intervals from calving to first service and to conception. These fertility parameters were also more favourable in low than in high genetic merit cows, but no interaction between diet and genetic merit was observed for any of these parameters. Genetic merit, but not diet, also affected the number of services required per conception and the conception rate. In conclusion, these results have confirmed that genetic selection for high milk yield is associated with a decrease in reproductive performance in dairy cows. More importantly, this study has demonstrated that it is possible to alleviate this problem by nutritional manipulation.

\section{Introduction}

Over the last few decades, the use of the pure Holstein breed and intense genetic selection have significantly increased milk yields of dairy cattle and, therefore, production efficiency of the dairy industry. Unfortunately, it has now become evident that this increase in milk yield is accompanied by some adverse consequences, such as an increase in the incidence of metabolic diseases, lameness and mastitis, and a reduction in reproductive performance (Pryce and Lovendahl, 1999; Ward and Parker, 1999; Webb et al., 1999a). This finding has given rise to the concern that the high yielding dairy cow may be under a state of metabolic stress during peak lactation and, therefore, the

Email: jin-gui.gong@bbsrc.ac.uk welfare and performance of other body functions are compromised (FAWC, 1997; Nielsen, 1999).

Observations have shown that reproductive performance has been decreasing in the high yielding dairy cow, especially when the animals are under severe negative energy balance (Butler and Smith, 1989; Nebel and McGilliard, 1993; Ouweltjes et al., 1996; Snijders et al., 2001). For example, intervals from calving to the first ovulation post partum and to conception have been observed to be longer in lactating cows with a higher milk yield than in cows with a low milk yield (Beam and Butler, 1999). Recent data have indicated that conception rate to first service has been declining by approximately 1.0 and $0.5 \%$ per annum in the UK (Royal et al., 2000) and the USA (Beam and Butler, 1999), respectively, over the last 25 years. Although this decline has been attributed, at least in part, to intense genetic selection based mainly on production traits, such as milk yield (Pryce et al., 1997; 
Pryce and Lovendahl, 1999), the underlying physiological mechanism remains poorly understood.

It has been well established that in cattle, as in most other mammalian species, ovarian function is controlled primarily by an integrated $\mathrm{GnRH}$-gonadotrophin-ovarian axis (Ireland, 1987; Fortune, 1994; Ginther et al., 1996; Roche, 1996; Webb et al., 1999b). However, recent work has shown that factors typically thought to be mainly involved in the regulation of metabolic processes, such as growth hormone, insulin and insulin-like growth factors (IGF), play an important part in the control of ovarian function in cattle (Gong et al., 1993; Spicer and Echternkamp, 1995; Gong and Webb, 1996; Lucy et al., 1999; Webb et al., 1999b). Therefore, it is likely that the changes in these factors associated with metabolic stress in the high yielding dairy cow alter the pattern of ovarian follicular growth and development during the early postpartum period, resulting in reduced reproductive function. Indeed, it has been shown that initiation of the first ovulation and, therefore, the resumption of normal oestrous cycles post partum is delayed in dairy cows selected for high genetic merit for milk yield, which is associated with a lower circulating insulin concentration (Gutierrez et al., 1999).

The aim of this study was to test further the above hypothesis by investigating the effect of dietary-induced changes in metabolic hormones on ovarian function during the early postpartum period. The main objective was to determine whether feeding a diet to increase circulating insulin concentrations for the first 50 days of the postpartum period could overcome the delay in the first ovulation post partum observed in high genetic merit dairy cows. In addition, the effect of the dietary treatment on the subsequent reproductive performance in terms of conception rate, interval from calving to the first service and service requirements was examined. With the use of the genetic lines undergoing selection for milk yield, it was also possible to assess the interaction between diet and the genetic merit of cows.

\section{Materials and Methods}

\section{Animals}

The experiment used the Roslin Institute's commercial Holstein-Friesian dairy herd, which has been undergoing selection for genetic merit for milk yield. Both the high and low genetic lines have a well balanced Holstein and Friesian background and the lines now have an established genetic difference of approximately $20 \%$ in a 305 day milk yield. The herd is managed to calve throughout the year and the animals used for this experiment calved between March and June. During the experiment, the cows were managed as in normal commercial practice: they were kept indoors, milked twice a day and fed a complete diet at the cubicles and concentrate supplements at the milking parlour. In accordance with the normal farm management practice, animals were available for rebreeding after day 50 post partum. The average parity (overall $2.8 \pm 0.2$ ) of the experimental cows was not different between high and low genetic lines.

All the experimental procedures were carried out in accordance with the Roslin Institute's Use of Experimental Animals in Research Code of Practice, under the UK Home Office Animals (Scientific Procedures) Act 1986.

\section{Experimental diets}

Diets were formulated to provide the energy and protein requirements (AFRC, 1993) for maintenance and milk production appropriate for the high (33 I milk per day) and low (27 I milk per day) genetic lines. Dietary ingredients were grass silage, whole-crop wheat silage, wheat, barley, sugar beet pulp, soya bean meal, protected fat (Megalac; Volac International, Royston) and a mineral/vitamin supplement. The proportions of ingredients were varied to produce two diets that were isoenergetic $(11.8 \mathrm{MJ}$ metabolizable energy $\mathrm{kg}^{-1}$ dry matter) and isonitrogenous (180 g crude protein $\mathrm{kg}^{-1}$ dry matter), but would encourage either acetate (100 g starch $\mathrm{kg}^{-1}$ dry matter) or propionate (260 g starch $\mathrm{kg}^{-1}$ dry matter) production in the rumen. The rationale was that acetate would result in normal concentrations of circulating insulin, but propionate would induce a greater insulin release in response to feeding. These two diets are referred to as control (C) and high insulin (I) diets. Both diets were fed as complete diets ad libitum and a commercial compound feed was given in the milking parlour at the rate of $1 \mathrm{~kg}$ per cow per day.

\section{Experimental procedures}

As animals from both high and low genetic lines were used, the experiment was a $2 \times 2$ factorial design $(n=10$ per group). High and low genetic merit cows were blocked separately by parity and expected calving date, and allocated randomly to the two diet groups. The animals were managed as in normal commercial practice before calving and were put on the experimental diets as soon as they left the calving pens. The experimental feeding continued for 50 days and the animals were then released to join the general herd. During the experimental feeding period, blood samples were collected each day by jugular venepuncture into glass tubes containing sodium citrate. Samples were centrifuged at $1000 \mathrm{~g}$ for $30 \mathrm{~min}$ at $4^{\circ} \mathrm{C}$ within $1 \mathrm{~h}$ of collection, and plasma was harvested and stored at $-20^{\circ} \mathrm{C}$ until assayed for concentrations of insulin, progesterone and FSH. Ovarian ultrasonography was carried out three times a week, starting from day 7 to day 10 after calving to determine the first ovulation post partum and patterns of ovarian follicular development. In addition, daily milk yield was recorded, and body weight and body condition score (on a scale from 1 to 5) were determined at the start of experimental feeding and then at weekly intervals. At the end of experimental feeding, whole milk samples were collected three times a week for a further 55 days, and preserved and stored at $4^{\circ} \mathrm{C}$ for subsequent 
measurement of progesterone concentrations. As part of the routine farm practice, reproductive performance data including service and pregnancy diagnosis outcome for all the trial cows were recorded and maintained in a database. These data were subsequently extracted to calculate the following fertility parameters: interval from calving to first service, interval from calving to conception, conception rate to first service, number of services required per conception and overall conception rate.

\section{Hormone assays}

For radioimmunoassay of all the hormones, as a routine at least three quality control samples with concentrations known to be high, intermediate and low in relation to the range of the standard curves were included in each assay. These quality control samples were used to determine the inter- and intra-assay coefficient of variation for each hormone. The assays were analysed using the AssayZap programme (Biosoft, Cambridge).

Insulin. Plasma insulin concentrations were measured using a specific double antibody radioimmunoassay as described and validated by Osmond et al. (1981) and Gong et al. (1993). The inter- and intra-assay ( $n=6$ assays) coefficients of variation were 8.2 and $6.9 \%$, respectively. The assay detection limit was $0.06 \mathrm{ng} \mathrm{ml}^{-1}$.

Progesterone. Plasma and whole milk progesterone concentrations were determined using a specific direct radioimmunoassay as validated by Law et al. (1992). lodinated progesterone label was obtained from Amersham Pharmacia Biotech (Little Chalfont). For plasma samples, the inter- and intra-assay ( $n=7$ assays) coefficients of variation were 8.3 and $5.4 \%$, respectively, and the assay detection limit was $0.12 \mathrm{ng} \mathrm{ml}^{-1}$. For milk samples, the inter- and intra-assay ( $n=4$ assays) coefficients of variation were 9.1 and $7.2 \%$, respectively, and the assay detection limit was $0.08 \mathrm{ng} \mathrm{ml}^{-1}$.

FSH. Plasma FSH concentrations were determined using a specific double antibody radioimmunoassay as described by Gong et al. (1995). The inter- and intra-assay $(n=4$ assays) coefficients of variation were 8.9 and $7.1 \%$, respectively. The assay sensitivity was $0.07 \mathrm{ng} \mathrm{ml}^{-1}$.

\section{Statistical analyses}

The data are presented as means \pm SEM whenever applicable. Statistical differences in milk yield, body weight, body condition score and plasma insulin concentrations were analysed by ANOVA for repeated measures. The main effects tested included diet ( $C$ and I), genetic merit (high and low), time (day post partum) and interactions. Data from reproductive measurements were analysed using either ANOVA (intervals from calving to first ovulation and number of services required per conception), survival analysis (interval from calving to first service and to conception) or chi-squared analysis (number of cows that ovulated within 50 days of calving and conception rate). Data from ultrasonography were recorded on videotapes and analysed as described by Gong et al. (1993) to determine the day of the first ovulation and patterns of follicular development. The effects of diet and genetic merit on plasma FSH concentrations were analysed by ANOVA for repeated measures after the data had been aligned to the first peak of FSH post partum. FSH profiles were also constructed for each cow and analysed in association with the pattern of follicular waves. For analyses on the relationship between FSH and follicular waves and follicle populations during each follicular wave, data were aligned to the emergence of the second postpartum follicular wave. The start of the second follicular wave was defined retrospectively as the day on which the dominant follicles were first detected by ultrasonography to be $5 \mathrm{~mm}$ or greater in diameter. Plasma and milk progesterone data were plotted individually and used to confirm the day of first ovulation post partum and subsequent fertility measurements.

Three cows (one from the high genetic group, one each from the low genetic group fed either a control (LC) or a high insulin diet (LI)) developed ovarian follicular cysts during the experiment. This was defined as persistence of dominant follicles of $>25 \mathrm{~mm}$ in diameter for over 10 days in the absence of a corpus luteum. Data from these cows were not included in the analyses of FSH and follicular dynamics. All three cows recovered spontaneously from the condition, as ovulations were detected after the end of experimental feeding by milk progesterone measurements. Therefore, they were included in the analyses of all the other measurements.

\section{Results}

\section{Milk yield, body weight and body condition score}

In all cows, milk yields increased gradually within the first 2 weeks of calving to reach a constant value that was then maintained throughout the rest of the experimental feeding period (interaction between genetic merit and time; not significant). The average daily milk yields during the experimental feeding period were $33.9 \pm 2.1$ for high genetic merit cows fed a high insulin $(\mathrm{HI})$ diet, $32.8 \pm 1.9$ for high genetic cows fed a control (HC) diet, $26.3 \pm 1.8$ for low genetic merit cows fed a high (LI) insulin diet and $27.7 \pm 1.7 \mathrm{~kg}$ for low genetic merit cows fed a control (LC) diet (effect of genetic merit, $P<0.01$; effect of diet and interaction between genetic merit and diet, not significant).

As no significant effect of diet or interaction between genetic merit and diet was observed on body weight and body condition score, data were pooled into high and low genetic merit groups ( $n=20$ per group) as shown (Figs 1 and 2). At the start of experimental feeding, high genetic merit cows weighed significantly $(P<0.01)$ more than low genetic cows although body condition score was similar 


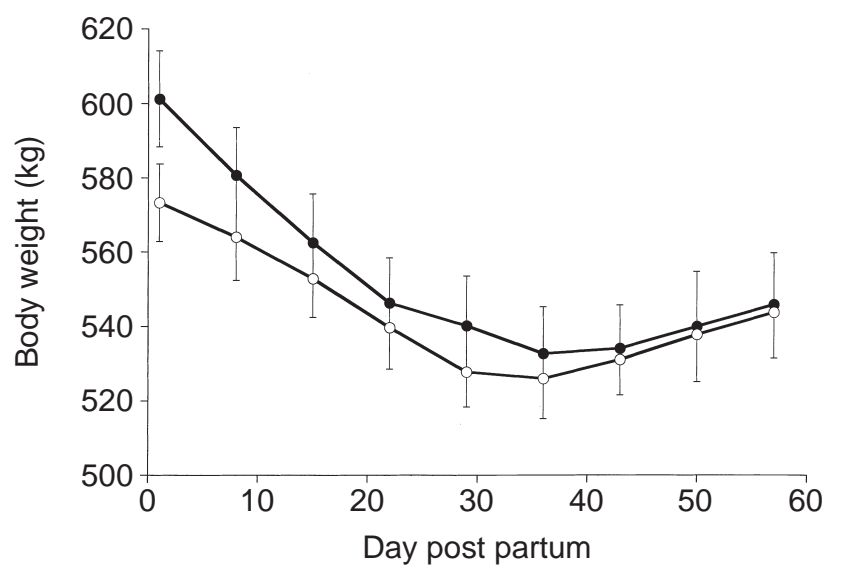

Fig. 1. Mean \pm SEM body weight for the high $(n=20 ; 0)$ and low $(n=20 ; \bigcirc)$ genetic merit cows. The measurements were taken on day 1 post partum (day of calving taken as day 0) and then at weekly intervals until day 57 post partum.

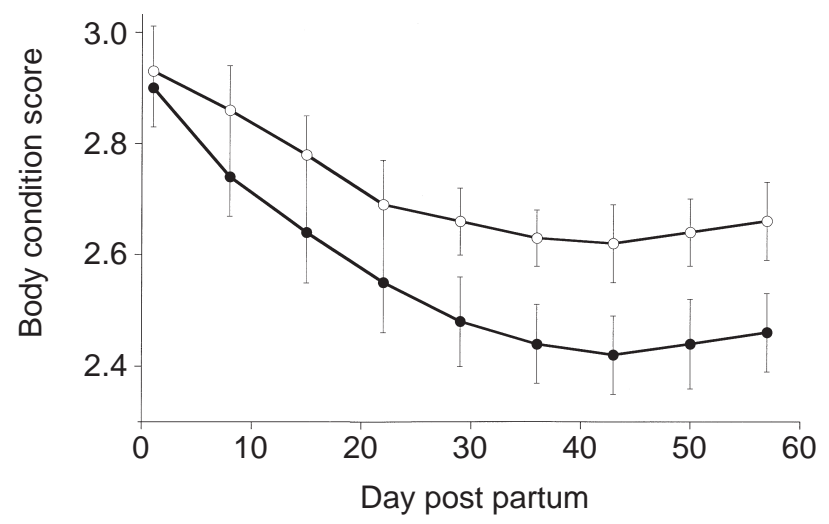

Fig. 2. Mean \pm SEM body condition score (on a scale from 1 to 5 ) for the high $(n=20 ; 0)$ and low $(n=20 ; \bigcirc)$ genetic merit cows. The measurements were taken on day 1 post partum (day of calving taken as day 0) and then at weekly intervals until day 57 post partum.

between the two groups. Both body weight and body condition score decreased with time during the first 5-6 weeks after calving in all cows, but the magnitude of the decrease was greater in high genetic merit cows than in low merit cows (effect of time, $P<0.01$; effect of genetic merit and interaction between genetic merit and time, not significant). Thereafter, body weight and body condition score gradually recovered throughout the remainder of the experimental feeding period.

\section{Plasma insulin concentrations}

Plasma insulin concentrations in all four groups decreased sharply during the first week post partum and then increased with time during the experimental feeding period (effect of time, $P<0.05$; Fig. 3 ). The high insulin diet

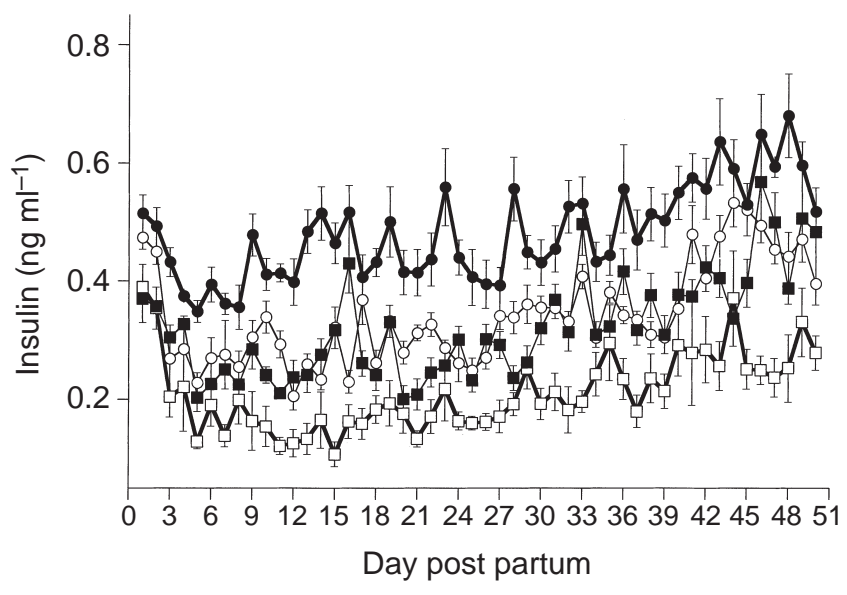

Fig. 3. Mean \pm SEM plasma insulin concentrations throughout the experimental feeding period for the four groups of cows $(n=10$ in each group). High genetic merit cows were fed a control ( $\square$ ) or high insulin ( $\mathbf{\square})$ diet, and low genetic merit cows were fed a control (O) or high insulin (-) diet from day 0 to day 50 post partum (day of calving taken as day 0). Plasma samples were collected each day throughout the experimental feeding period.

increased circulating insulin concentrations in both high and low genetic merit cows (effect of diet, $P<0.01$; interaction between diet and time, not significant). The average insulin concentrations throughout the experimental feeding period were $0.32 \pm 0.015,0.21 \pm 0.011,0.48 \pm 0.021$ and $0.34 \pm 0.016 \mathrm{ng} \mathrm{ml}^{-1}$ for HI, HC, LI and LC groups, respectively. The dietary effect was observed within 3-4 days after the start of experimental feeding and was maintained throughout the rest of the experimental feeding period. Genetic merit also had a significant $(P<0.01)$ effect on circulating insulin concentrations and insulin concentrations were lower in the high genetic merit cows (interaction between genetic merit and time, not significant). There was no significant interaction between diet and genetic merit.

\section{Plasma FSH and ovarian follicular development}

When analysed individually, plasma FSH concentrations started to increase within 3-5 days of calving in all the cows and then fluctuated every $7-10$ days in a regular wave pattern throughout the rest of sampling period. When data were aligned to the first peak of FSH post partum, no effects of diet or genetic merit on either wave pattern or concentrations were observed. Mean FSH concentrations throughout the experimental feeding period were $0.62 \pm 0.02$, $0.60 \pm 0.02,0.59 \pm 0.02$ and $0.61 \pm 0.02 \mathrm{ng} \mathrm{ml}^{-1}$ for $\mathrm{HI}$, $\mathrm{LI}, \mathrm{HC}$ and LC groups, respectively.

When ultrasound scanning started 7-10 days after calving, most of the cows had already developed a dominant follicle. Thereafter, continuous turnover in follicular waves was observed throughout the experimental feeding period except when ovulation occurred. Most of the cows did not 
Table 1. Proportion of animals that ovulated within 50 days of calving, and the interval from calving to the first postpartum ovulation in high and low genetic merit dairy cows fed with a high insulin or control diet for the first 50 days post partum

\begin{tabular}{lccccc}
\hline & \multicolumn{2}{c}{ Proportion of cows } & & \multicolumn{2}{c}{ Interval (days) } \\
\cline { 2 - 3 } \cline { 5 - 6 } & High insulin diet & Control diet & & High insulin diet & Control diet \\
\hline High genetic merit cows & $8 / 10$ & $5 / 10$ & & $41.4 \pm 4.9$ & $53.8 \pm 7.7$ \\
Low genetic merit cows & $10 / 10$ & $6 / 10$ & & $27.5 \pm 1.9$ & $43.1 \pm 5.2$ \\
\hline
\end{tabular}

$n=10$ cows per group.

Table 2. Fertility parameters as derived from the farm breeding records and milk progesterone profiles in high and low genetic merit dairy cows fed with a high insulin or control diet for the first 50 days post partum

\begin{tabular}{|c|c|c|}
\hline & High insulin diet & Control diet \\
\hline \multicolumn{3}{|l|}{ High genetic merit cows } \\
\hline Interval from calving to first service (days) ${ }^{a}$ & $128.2 \pm 14.8(n=9)$ & $139.8 \pm 16.7(n=8)$ \\
\hline Interval from calving to conception (days) ${ }^{b}$ & $153.1 \pm 17.9(n=6)$ & $169.5 \pm 20.4(n=5)$ \\
\hline Conception rate to first service* & $4 / 9(44.4 \%)$ & $3 / 8(37.5 \%)$ \\
\hline Number of services per conception ${ }^{c}$ & $2.1 \pm 0.3(n=6)$ & $1.9 \pm 0.3(n=5)$ \\
\hline Overall conception rate ${ }^{b *}$ & $6 / 9(66.7 \%)$ & $5 / 8(62.5 \%)$ \\
\hline \multicolumn{3}{|l|}{ Low genetic merit cows } \\
\hline Interval from calving to first service (days) ${ }^{\mathrm{a}}$ & $104.6 \pm 9.3(n=9)$ & $113.5 \pm 10.4(n=8)$ \\
\hline Interval from calving to conception (days) & $116.4 \pm 11.8(n=9)$ & $128.6 \pm 13.7(n=8)$ \\
\hline Conception rate to first service* & $6 / 9(66.7 \%)$ & $5 / 8(62.5 \%)$ \\
\hline Number of services per conceptionc & $1.2 \pm 0.2(n=9)$ & $1.4 \pm 0.2(n=8)$ \\
\hline Overall conception rate ${ }^{\mathrm{b} *}$ & $9 / 9(100 \%)$ & $8 / 8(100 \%)$ \\
\hline
\end{tabular}

a Overall, 34 of 40 cows were served; *based on pregnancy diagnosis outcome.

bTwenty-eight of 34 cows that were served eventually conceived.

'Only data from those cows that conceived are included.

ovulate the first dominant follicle of the postpartum period. When data were aligned to the emergence of the second postpartum follicular wave, a close association between FSH and follicular wave pattern was observed (Fig. 4). There were no significant effects of either genetic merit or diet on this relationship and the pattern of follicular development, including maximum size and growth rate of dominant follicles, and numbers of medium sized $(5-8 \mathrm{~mm}$ in diameter) and small ( $<5 \mathrm{~mm}$ in diameter) follicles detected during each follicular wave.

\section{Day of the first ovulation post partum}

As detected by ultrasonography and confirmed by plasma progesterone measurements (or milk progesterone profiles in those cows that did not ovulate within 50 days post partum), the proportion of cows that ovulated within 50 days post partum and the interval from calving to the first ovulation are shown (Table 1). The high insulin diet significantly $(P<0.05)$ increased the proportion of cows ovulating within 50 days of calving. Fewer high genetic merit cows ovulated within this time frame, but the effect was not significant. Furthermore, the high insulin diet significantly $(P<0.01)$ reduced the interval from calving to first ovulation. Genetic merit also had a significant $(P<0.05)$ effect on the interval from calving to first ovulation, but no interaction between diet and genetic merit was observed.

\section{Fertility performance measurements}

Fertility performance data derived from the farm breeding records and milk progesterone profiles for the four groups are shown (Table 2). Although the high insulin diet reduced the intervals from calving to the first service and to conception, the effect was not significant. However, the effect of genetic merit on these two measurements was significant $(P<0.05)$. For conception rate to the first service, overall conception rate and number of services required per conception, the effects of genetic merit were significant $(P<0.05)$, but diet did not have a significant effect on any of these measurements. The number of cows included for each measurement was not always ten per group, as some cows were never served or were served but failed to conceive. 

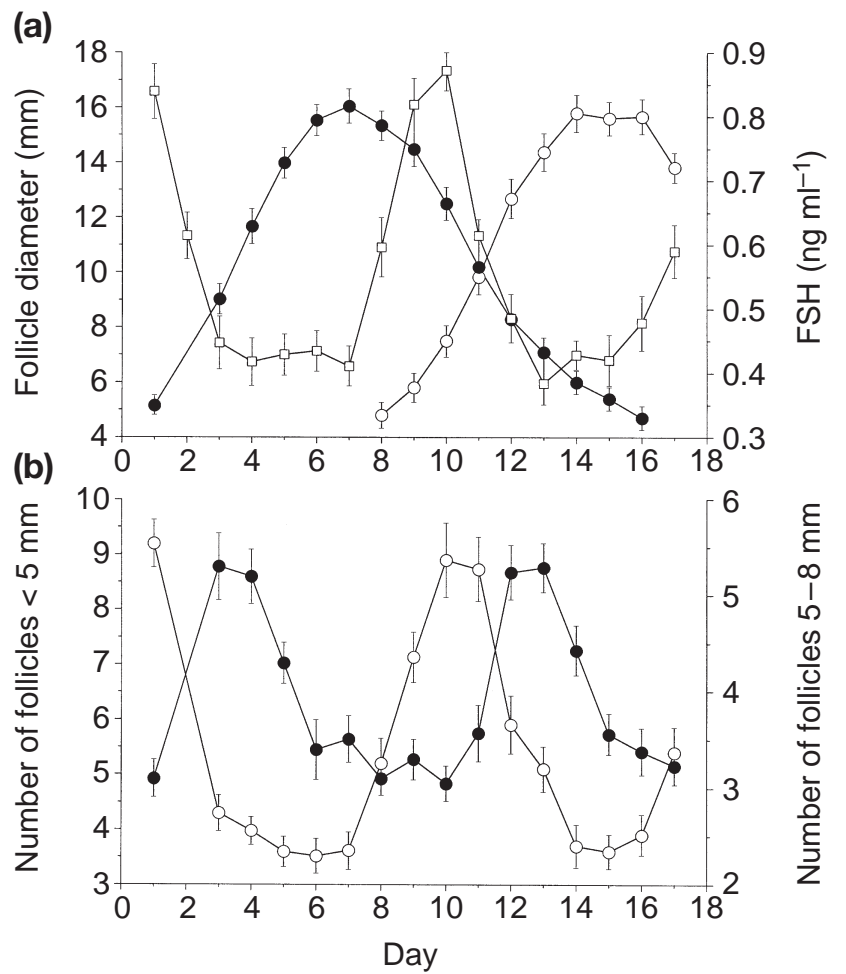

Fig. 4. Patterns of dominant follicle development ( $\bigcirc$ and $\mathbf{O})$ (a) in relation to plasma FSH profiles ( $\square$ ) (a) and mean \pm SEM numbers of small $(<5 \mathrm{~mm}, \bigcirc)$ and medium-sized (5-8 mm, - (b) follicles detected during each follicular waves in all the cows used in the experiments except the three with follicular cysts $(n=37)$. Plasma samples were collected each day and ovarian ultrasonography was carried out three times each week (Monday, Wednesday and Friday) throughout the experimental feeding period. Data were aligned to the emergence of the second postpartum follicular wave. This was defined retrospectively as the day (represented as day 1 on the horizontal axis) when the dominant follicle was first detected by ultrasonography to be $5 \mathrm{~mm}$ or greater in diameter.

\section{Discussion}

It has previously been shown that the first ovulation post partum is delayed in dairy cows undergoing selection for genetic merit for milk yield in association with changes in circulating metabolic hormone profiles (Gutierrez et al., 1999). Results from the present study have confirmed and extended these previous observations, indicating that feeding a diet to increase circulating insulin concentrations during early lactation can advance the first ovulation post partum without affecting patterns of plasma $\mathrm{FSH}$ and ovarian follicular development.

It has now become evident that reproductive performance has been decreasing in the high yielding dairy cow. A large number of studies using correlation analysis (Nebel and McGilliard, 1993; Campos et al., 1994; Hoekstra et al., 1994; Ouweltjes et al., 1996; Pryce et al., $1997,1999)$ have found that milk yields and genetic merit for milk production are negatively associated with fertility traits. Other studies (Beam and Butler 1997; Darwash et al., 1999; Gutierrez et al., 1999; Gong et al., 2000; Royal et al., 2000; Snijders et al., 2001) measuring directly the physiological parameters have produced similar data to show that reproductive function during the early postpartum period and subsequent fertility are reduced in animals with a higher genetic merit or a higher milk yield. The current study has confirmed these observations and extended previous results (Gutierrez et al., 1999), indicating that the intervals from calving to first ovulation, to first service and to conception are longer in cows selected for higher genetic merit for milk yield. In addition, conception rate to first service is lower and the number of services required per conception is greater in high than in low genetic merit cows.

Although it is clear that fertility is declining in high yielding dairy cows, the reason is not well understood. In Friesian populations it has been suggested that decrease in fertility may have been caused by the introduction of Holstein genes (Hoekstra et al., 1994; Royal et al., 2000; Snijders et al., 2001). However, when Holstein populations have always been used, a similar decline in fertility in association with increased milk yield has also been reported (Campos et al., 1994; Foote, 1996; Beam and Butler, 1999). The Roslin Institute dairy herd used in the current study has been undergoing selection for genetic merit for milk yield for the last 20 years. A closely controlled breeding scheme has ensured that the high and low lines have a wellbalanced Holstein and Friesian background. As expected, high genetic merit cows produced more milk throughout the experimental period, supporting the notion that a decrease in reproductive function is associated with an increase in milk yields (Beam and Butler, 1999; Pryce and Lovendahl, 1999; Royal et al., 2000). However, whether milk yield per se is responsible for the decline in fertility remains equivocal. Although genetic analyses have generally revealed a negative correlation between fertility and milk production traits (Pryce and Lovendahl, 1999), some studies have found that in both high and medium genetic merit cows, milk yield in animals that conceive after the first service is not significantly different from animals that fail to conceive (Snijders et al., 2001).

It has also been proposed that reproductive performance of high yielding cows is compromised as a result of increased negative energy balance during early lactation (Staples et al., 1990; Kruip et al., 1996; Beam and Butler, 1999). Owing to the difference between dietary energy intake and requirements for milk production, high yielding dairy cows typically experience a period of negative energy balance during early lactation which results in mobilization of body fat reserves (Veerkamp and Koenen, 1999). The extent of negative energy balance is normally related to milk yield (Butler and Smith, 1989; Beam and Butler, 1999). The current study has confirmed these observations, showing that cows were under negative energy balance for the first 5-6 weeks after calving. Moreover, high genetic merit cows lost significantly more body condition scores 
and body weight during this period. Several studies have shown that negative energy balance status can significantly influence functional characteristics of ovarian follicular development during the early postpartum period and, therefore, affect the resumption of oestrous cycles, interval from calving to the first ovulation and subsequent fertility (Staples et al., 1990; Lucy et al., 1992; Kruip et al., 1996; Beam and Butler, 1997, 1999). However, other studies have reported that the interval from calving to the first ovulation is not related to energy balance or genetic merit of cows (Villa-Godoy et al., 1988; Snijders et al., 2001), and that changes in body condition score from calving to first service are not correlated with conception in high genetic merit cows (Snijders et al., 2001).

In agreement with the findings of Beam and Butler (1997, 1999), the present study indicates that re-establishment of FSH secretion and ovarian follicular development do not appear to be limiting factors causing the delay in the first postpartum ovulation. Circulating $\mathrm{FSH}$ concentrations increased within 1 week of calving in all cows and initiated the first wave of follicular development. Most of the cows had already developed a dominant follicle when ultrasonography started 7-10 days after calving. Thereafter, regular turnover in follicular waves associated with FSH was present throughout the period of ultrasonography, only being interrupted by ovulation. The patterns of FSH secretion and follicular development were not affected by diet or genetic merit, and were typical of cattle during both the oestrous cycles (Adams et al., 1992; Gong et al., 1995) and the early postpartum period (Rajamahendran and Taylor, 1990; Savio et al., 1990; Beam and Butler, 1997). These results have indicated that the more likely limiting factor causing the delay in the first ovulation post partum is the mechanism responsible for ovulation, which includes functional competence of dominant follicle and LH secretion. Indeed, the steroidogenic activity of dominant follicles and LH release pattern during early lactation, and their relationships to subsequent fertility are affected by the energy balance status of cows (Staples et al., 1990; Lucy et al., 1992; Schillo, 1992; Kruip et al., 1996; Beam and Butler, 1997, 1999). However, whether there is a similar effect of genetic merit on these functional aspects of follicular development and LH secretion during the early post partum period remains to be determined. Moreover, although it has been suggested that conception rate to first service is reduced in cows with delayed first ovulation post partum (Lucy et al., 1992; Beam and Butler, 1999), the influences of genetic merit and energy balance status on oocyte competence and early embryonic development need to be clarified (Snijders et al., 2000).

The physiological mechanism underlying the decline in reproductive function in modern dairy cows is not well understood. Recent work has established that metabolic hormones, including $\mathrm{GH}$, insulin and IGF have a pronounced influence on ovarian follicular development, oocyte maturation and early embryonic development in cattle (Gong et al., 1993; Spicer and Echternkamp, 1995;
Gong and Webb, 1996; Beam and Butler, 1999; Lucy et al., 1999; Webb et al., 1999a,b). Therefore, it was hypothesized that changes in these factors in high yielding dairy cows can alter normal reproductive function during the early postpartum period, resulting in reduced fertility. Indeed, metabolic hormones might provide a common control mechanism for reproduction and lactation in lactating dairy cows (Ward and Parker, 1999). In support of this hypothesis, Gutierrez et al. (1999) demonstrated that the delay in the resumption of oestrous cycles post partum, observed in dairy cows selected for high genetic merit for milk yield, was associated with alterations in metabolic hormone profiles. This finding is in accordance with other studies showing that greater negative energy balance during early lactation is associated with changes in plasma growth hormone, IGF-I and insulin concentrations and prolonged intervals from calving to first ovulation (Beam and Butler, 1997, 1999).

The results from the current study have provided further evidence to support this hypothesis. First, it was confirmed that the delay in the first ovulation post partum observed in high genetic merit cows is associated with a lower circulating insulin concentration. More importantly, the diet resulting in a higher circulating insulin concentration reduced the interval from calving to the first ovulation in both high and low genetic merit cows. This diet also reduced the intervals from calving to the first service and to conception, presumably as a consequence of the effect on the first ovulation post partum. This contention is consistent with the observation that regular turnover in follicular development occurred after the first ovulation post partum in most cows in the current study and other studies (Beam and Butler, 1997, 1999). However, the subsequent fertility parameters, including conception rate to first service and number of services required per conception, were not affected by diet. The reason for this is not clear although it is possible that the duration of experimental feeding was not long enough, as most of the cows were not served until some time after the experimental feeding had ended.

The mechanisms through which insulin acted to affect the time of the first ovulation post partum are not clear. Insulin is a potent stimulator for the differentiation and steroidogenesis of bovine follicular cells in vitro (Spicer and Echternkamp, 1995; Gong and Webb, 1996; Webb et al., 1999b). It is likely that increased insulin concentrations promoted the differentiation and maturation of dominant follicles during early lactation, thereby increasing the chance of these dominant follicles ovulating in response to the LH surge (Beam and Butler, 1997, 1999). This suggestion is consistent with our more recent results (J. G. Gong, A. Moghaddam, G. Baxter, P. C. Garnsworthy, R. Webb and D. G. Armstrong, unpublished) showing that the high insulin diet did not affect circulating IGF-I concentrations or the pulsatile secretion of $\mathrm{LH}$.

In summary, the results from this study confirm that genetic selection for high milk yield is associated with a decrease in reproductive performance in dairy cows. In 
addition, feeding a diet to increase circulating insulin concentrations during early lactation can advance the first postpartum ovulation. More importantly, this was achieved without a negative influence on both milk yield and energy balance status of the cows, indicating that it is possible to alleviate the fertility problem in high yielding dairy cows by using appropriate management practices, such as nutritional manipulation. However, further work is required to determine the effects of the dietary treatment on fertility.

This work was supported by the Scottish Executive Rural Affairs Department. The authors would like to thank NHPP and USDA Animal Hormone Programme, and Diagnostics Scotland for the reagents for radioimmunoassays. The authors also extend their thanks to the staff at the Roslin Institute's Blythbank Farm for the care, management and handling of experimental animals, and to K. D. Troup and E. McCullough for technical assistance.

\section{References}

Adams GP, Matteri RL, Kastelic JP, Ko JCH and Ginther OJ (1992) Association between surges of FSH and the emergence of follicular waves in heifers Journal of Reproduction and Fertility 94 177-188

AFRC (1993) Energy and protein requirements of ruminants An Advisory Manual Prepared by the AFRC Technical Committee on Responses to Nutrients CAB International, Wallingford

Beam SW and Butler WR (1997) Energy balance and ovarian follicle development prior to the first ovulation postpartum in dairy cows receiving three levels of dietary fat Biology of Reproduction 56 133-142

Beam SW and Butler WR (1999) Energy balance effects on follicular development and first ovulation in post-partum cows Journal of Reproduction and Fertility Supplement 54 411-424

Butler WR and Smith RD (1989) Interrelationships between energy balance and post partum reproductive function in dairy cattle Journal of Dairy Science 72 767-783

Campos MS, Wilcox CJ, Beceril CM and Diz A (1994) Genetic parameters for yield and reproductive traits of Holstein and Jersey cattle in Florida Journal of Dairy Science 77 867-873

Darwash AO, Lamming GE and Woolliams JA (1999) The potential for identifying heritable endocrine parameters associated with fertility in post-partum dairy cows Animal Science 68 333-347

FAWC (1997) Report on the welfare of dairy cattle Farm Animal Welfare Council pp 96, Surbiton, UK

Foote RH (1996) Review: dairy cattle reproductive physiology research and management - past progress and future prospects Journal of Dairy Science 79 980-990

Fortune JE (1994) Ovarian follicular growth and development in mammals Biology of Reproduction $\mathbf{5 0} 225-232$

Ginther OJ, Wiltbank MC, Fricke PM, Gibbons JR and Kot K (1996) Mini review: selection of the dominant follicle in cattle Biology of Reproduction 55 1187-1194

Gong JG and Webb R (1996) Control of ovarian follicle development in domestic ruminants: its manipulation to increase ovulation rate and improve reproductive performance Animal Breeding Abstracts 64 195-204

Gong JG, Bramley TA and Webb R (1993) The effect of recombinant bovine somatotrophin on ovarian follicular growth and development in heifers Journal of Reproduction and Fertility 97 247-254

Gong JG, Bramley TA, Gutierrez CG, Peters AR and Webb R (1995) Effects of chronic treatment with a gonadotrophin-releasing hormone agonist on peripheral concentrations of $\mathrm{FSH}$ and $\mathrm{LH}$, and ovarian function in heifers Journal of Reproduction and Fertility 105 263-270

Gong JG, Lee WJ and Moghaddam A (2000) LH secretion and response to $\mathrm{GnRH}$ during the early postpartum period in dairy cows undergoing genetic selection for milk yield Journal of Reproduction and Fertility Abstract Series $\mathbf{2 5}$ Abstract 57
Gutierrez CG, Gong JG, Bramley TA and Webb R (1999) Effects of genetic selection for milk yield on metabolic hormones and follicular development in postpartum dairy cattle Journal of Reproduction and Fertility Abstract Series $\mathbf{2 4}$ Abstract 32

Hoekstra J, van de Lugt AW, van de Werf JHJ and Ouweltjes W (1994) Genetic and phenotypic parameters for milk production and reproductive performance traits in upgraded dairy cattle Livestock Production Science $\mathbf{4 0} 225-232$

Ireland JJ (1987) Control of follicular growth and development Journal of Reproduction and Fertility Supplement 34 39-54

Kruip TAM, van der Werf JHJ and Wensing T (1996) Energy balance in early lactation of high producing dairy cows and its relation to reproduction, health and welfare European Association for Animal Production Publication 84 45-57

Law AS, Baxter G, Logue DN, O'Shea T and Webb R (1992) Evidence for the action of a bovine follicular fluid factor(s) other than inhibin in suppressing follicular development and delaying oestrus in heifers Journal of Reproduction and Fertility 96 603-616

Lucy MC, Staples CR, Thatcher WW, Erickson PS, Cleale RM, Firkins JL, Clark JH, Murphy MR and Brodie BO (1992) Influence of diet composition, dry matter intake, milk production and energy balance on time of postpartum ovulation and fertility in dairy cows Animal Production 54 323-331

Lucy MC, Bilby CR, Kirby CJ, Yuan W and Boyd CK (1999) Role of growth hormone in development and maintenance of follicles and corpora lutea Journal of Reproduction and Fertility Supplement 54 49-59

Nebel RL and McGilliard ML (1993) Interactions of high milk yield and reproductive performance in dairy cows Journal of Dairy Science $\mathbf{7 6}$ 3257-3268

Nielsen BL (1999) Perceived welfare issues in dairy cattle, with special emphasis on metabolic stress British Society of Animal Science Occasional Publication 24 1-7

Osmond TJ, Carr WR, Hinks CJM, Land RB and Hill WG (1981) Physiological attributes as possible selection criteria for milk production: 2. Plasma insulin, triiodothyroxine and thyroxine in bull Animal Production 32 159-163

Ouweltjes W, Smolders EAA, van Eldik P, Elving L and Schukken YH (1996) Herd fertility parameters in relation to milk production in dairy cattle Livestock Production Science 46 221-227

Pryce JE and Lovendahl P (1999) Options to reduce vulnerability to metabolic stress by genetic selection British Society of Animal Science Occasional Publication 24 119-128

Pryce JE, Veerkamp RF, Thompson R, Hill WG and Simm G (1997) Genetic aspects of common health disorders and measures of fertility in Holstein Friesian dairy cattle Animal Science 65 353-360

Pryce JE, Nielsen BL, Veerkamp RF and Simm G (1999) Genotype and feeding system effects and interactions for health and fertility traits in dairy cattle Livestock Production Science 57 193-201

Rajamahendran R and Taylor C (1990) Characterization of ovarian activity in postpartum dairy cows using ultrasound imaging and progesterone profiles Animal Reproduction Science 22 171-180

Roche JF (1996) Control and regulation of folliculogenesis: a symposium in perspective Reviews of Reproduction 1 19-27

Royal MD, Darwash AO, Flint APF, Webb R, Woolliams JA and Lamming GE (2000) Declining fertility in dairy cattle: changes in traditional and endocrine parameters of fertility Animal Science 70 487-501

Savio JD, Boland MP, Hynes N and Roche JF (1990) Resumption of follicular activity in the early postpartum period of dairy cows Journal of Reproduction and Fertility 88 569-579

Schillo KK (1992) Effects of dietary energy on control of luteinizing hormone secretion in cattle and sheep Journal of Animal Science 70 1271-1282

Snijders SEM, Dillon P, O'Callaghan D and Boland MP (2000) Effect of genetic merit, milk yield, body condition and lactation number on in vitro oocyte development in dairy cows Theriogenology $\mathbf{5 3}$ 981-989

Snijders SEM, Dillon PG, O'Farrell KJ, Diskin M, Wylie ARG, $\mathrm{O}^{\prime}$ Callaghan D, Rath M and Boland MP (2001) Genetic merit for milk production and reproductive success in dairy cows Animal Reproduction Science $\mathbf{6 5}$ $17-31$ 
Spicer LJ and Echternkamp SE (1995) The ovarian insulin and insulin-like growth factor system with an emphasis on domestic animals Domestic Animal Endocrinology 12 223-245

Staples CR, Thatcher WW and Clark JH (1990) Relationship between ovarian activity and energy status during the early postpartum period of high producing dairy cows Journal of Dairy Science 73 938-947

Veerkamp RF and Koenen EPC (1999) Genetics of food intake, live weight, condition score and energy balance British Society of Animal Science Occasional Publication 24 63-73

Villa-Godoy A, Hughes TL, Emery RS, Chapin LT and Fogwell RL (1988) Association between energy balance and luteal function in lactating dairy cows Journal of Dairy Science 71 1063-1072

Ward WR and Parker CS (1999) Field evidence of metabolic stress in dairy cow British Society of Animal Science Occasional Publication 24 21-26
Webb R, Garnsworthy PC, Gong JG, Robinson RS and Wathes DC (1999a) Consequences for reproductive function of metabolic adaptations to load British Society of Animal Science Occasional Publication 24 99-112

Webb R, Campbell BK, Garverick HA, Gong JG, Gutierrez CG and Armstrong DG (1999b) Molecular mechanisms regulating follicular recruitment and selection Journal of Reproduction and Fertility Supplement $\mathbf{5 4}$ 33-48

Received 17 July 2001.

First decision 11 October 2001.

Accepted 14 November 2001. 